The Physiological Strain Index Modified for Trained Heat Acclimatized Individuals in Outdoor Heat

\title{
Byrne, Chris
}

http://hdl.handle.net/10026.1/13096

\subsection{3/ijspp.2018-0506 \\ International Journal of Sports Physiology and Performance \\ Human Kinetics}

All content in PEARL is protected by copyright law. Author manuscripts are made available in accordance with publisher policies. Please cite only the published version using the details provided on the item record or document. In the absence of an open licence (e.g. Creative Commons), permissions for further reuse of content should be sought from the publisher or author. 
2

3

5

6

7

8 Christopher Byrne ${ }^{1}$ and Jason K.W. Lee

9

12

13

14

15

16

17 Preferred running head: Modified physiological heat strain index

18 Abstract word count: 250

19 Text word count: 3990

20 Singapore.

20 Number of figures and tables: 4 figures, 4 tables.

\section{The Physiological Strain Index Modified for Trained Heat Acclimatized Individuals in Outdoor Heat}

${ }^{1}$ School of Health Professions, Faculty of Health and Human Sciences, University of Plymouth, UK. ${ }^{2}$ Yong Loo Lin School of Medicine, National University of Singapore, Republic of

Corresponding author: Dr Chris Byrne, School of Health Professions, Faculty of Health and Human Sciences, University of Plymouth, Peninsula Allied Health Centre, Derriford Road, Plymouth, PL6 8BH, UK. Tel: +44 (0)1752 587557. Email: chris.byrne@ plymouth.ac.uk 


\section{Abstract}

22 Purpose: To determine if the physiological strain index (PSI), in original or modified form, 23 can evaluate heat strain on a 0-10 scale, in trained and heat acclimatized men undertaking a 24 competitive half-marathon run in outdoor heat.

Methods: Core (intestinal) temperature (TC) and heart rate (HR) were recorded continuously in 24 males (mean $\pm \mathrm{SD}$ age: $26 \pm 3$ years; $\mathrm{VO}_{2 \text { peak }} 59 \pm 5 \mathrm{ml} \cdot \mathrm{kg} \cdot \mathrm{min}^{-1}$ ). Four versions of the PSI were computed: original PSI with upper constraints of TC $39.5^{\circ} \mathrm{C}$ and HR $180 \mathrm{~b} \cdot \mathrm{min}^{-1}$ (PSI ${ }_{39.5 / 180)}$; and three modified versions of PSI with each having an age-predicted maximal $\mathrm{HR}$ constraint and graded TC constraints of $40.0^{\circ} \mathrm{C}$ ( $\left.\mathrm{PSI}_{40.0 / \mathrm{PHRmax}}\right), 40.5^{\circ} \mathrm{C}$ ( $\mathrm{PSI}_{40.5 / \mathrm{PHRmax}}$ ), and $41.0^{\circ} \mathrm{C}\left(\mathrm{PSI}_{41.0 / \mathrm{PHRmax}}\right)$.

Results: In a warm $\left(26.1-27.3^{\circ} \mathrm{C}\right)$ and humid $(79-82 \%)$ environment, all runners finished the race asymptomatic in $107 \pm 10$ (91-137) minutes. Peak TC and HR were $39.7^{\circ} \mathrm{C} \pm 0.5(38.5-$ $\left.40.7^{\circ} \mathrm{C}\right)$ and $186 \pm 6(175-196) \mathrm{b} \cdot \mathrm{min}^{-1}$, respectively. Sixty-three percent exceeded TC $39.5^{\circ} \mathrm{C}$, $71 \%$ exceeded HR $180 \mathrm{~b} \cdot \mathrm{min}^{-1}$, and $50 \%$ exceeded both of the original PSI upper TC and HR constraints. The computed heat strain was significantly greater with $\mathrm{PSI}_{39.5 / 180}$ than all other methods $(P<0.003)$. PSI $>10$ was observed in $63 \%$ of runners with $\mathrm{PSI}_{39.5 / 180}, 25 \%$ for $\mathrm{PSI}_{40.0 / \mathrm{PHR} \max }, 8 \%$ for $\mathrm{PSI}_{40.5 / \mathrm{PHR} \max }$, and $0 \%$ for $\mathrm{PSI}_{41.0 / \mathrm{PHR} \max }$.

Conclusion: The PSI was able to quantify heat strain on a $0-10$ scale in trained and heat acclimatized men undertaking a half-marathon race in outdoor heat, but only when the upper TC and HR constraints were modified to $41.0^{\circ} \mathrm{C}$ and age-predicted maximal HR, respectively. 
During exercise in hot environments, heat stress refers to the thermal load imposed by environmental and metabolic conditions whereas heat strain refers to the physiological consequences of heat stress. ${ }^{1}$ The ability to monitor the heat strain of individuals in the field is an attractive proposition, as this would provide useful data on heat strain during training and competition, heat acclimatization status, and the effectiveness of interventions aimed at mitigating heat strain. A potential candidate is the physiological strain index (PSI), introduced by Moran and colleagues in $1998^{2}$ as a novel and simple method of evaluating heat strain with potential for universal use. ${ }^{3}$ The PSI combines normalized increases in core temperature (TC) and heart rate (HR) to produce an instantaneous measure of strain on a $0-10 \mathrm{scale}^{2,3}$. The PSI has demonstrated validity in discriminating between levels of heat strain during laboratory experimental manipulations of environmental heat, ${ }^{2}$ heat acclimation status, ${ }^{4}$ aerobic fitness status, ${ }^{4}$ hydration status, ${ }^{5}$ and exercise intensity levels. ${ }^{5}$ The merits of the PSI include its simple calculation, use of a 0-10 scale with ease of interpretation, sensitivity to rest and recovery periods, and potential for real-time use. ${ }^{3}$ By employing two physiological responses (i.e. TC and HR) that can be measured simultaneously in the field, ${ }^{6-8}$ the PSI offers utility as a heat strain monitoring tool for individuals performing in the natural environment.

The external validity and utility of the PSI for trained and heat acclimatized individuals is currently limited by the upper TC and HR constraints of $39.5^{\circ} \mathrm{C}$ and $180 \mathrm{~b} \cdot \mathrm{min}^{-1}$, respectively; which serve to constrain TC and HR contributions to 0-5 values and their sum to a 0-10 scale. The original choice of these constraints is understandable since the PSI was developed and validated on databases of humans exercising in simulated laboratory heat where these physiological thresholds (i.e. TC $39.5^{\circ} \mathrm{C}$ and $\mathrm{HR} 180 \mathrm{~b} \cdot \mathrm{min}^{-1}$ ) are typical ethical ceiling end-points. ${ }^{2,4,5}$ Whilst these constraints may be appropriate for maintaining safety in laboratory studies, our premise is that they are too low for application to trained and heat acclimatized individuals who commonly exceed TC $39.5^{\circ} \mathrm{C}$ and HR $180 \mathrm{~b} \cdot \mathrm{min}^{-1}$. Widespread evidence of trained individuals exceeding $\mathrm{TC} 39.5^{\circ} \mathrm{C}$ and/or $\mathrm{HR} 180 \mathrm{~b} \cdot \mathrm{min}^{-1}$ during training and competition in a variety of sports exists (e.g. cycling, ${ }^{9,10}$ distance running, ${ }^{6,11}$ football codes, ${ }^{8,12,13}$ and tennis $\left.{ }^{14}\right)$. In 11 runners undertaking an $8 \mathrm{~km}$ running race in WBGT 26-28 ${ }^{\circ} \mathrm{C}$, Ely et al. ${ }^{7}$ observed that $100 \%$ of runners had peak TC $>39.5^{\circ} \mathrm{C}\left(39.7-40.9^{\circ} \mathrm{C}\right)$ and peak HR was $186(175-195) \mathrm{b} \cdot \mathrm{min}^{-1}$. Unless the upper TC and HR constraints of the PSI are increased to accommodate these higher physiological responses, the PSI will over-estimate the heat strain of trained individuals, and their physiological responses could result in PSI ratings exceeding and invalidating the $0-10$ scale.

Endurance trained individuals have the potential to produce $\mathrm{TC}>39.5^{\circ} \mathrm{C}$ due to their higher rates of metabolic heat production ${ }^{15,16}$ and enhanced tolerance to high TC. ${ }^{17,18}$ The potential to produce HR $>180 \mathrm{~b} \cdot \mathrm{min}^{-1}$ is due to this value representing a high but submaximal HR until $>40$ years of age, ${ }^{19,20}$ the high exercise intensities produced in training and competition $^{7,8,10,12,21,22}$ and the elevated HR response associated with heat stress. ${ }^{1,23}$ Our premise is that modification of PSI TC and HR upper constraints is required to reflect the magnitude of the physiological responses produced by trained and heat acclimatized individuals in heat. Support for this premise was provided by Tikuisis et al. ${ }^{24}$ who reported that PSI and a perceptual strain equivalent were significantly different in trained (lower perceived strain) but not untrained individuals when the TC constraint was $39.5^{\circ} \mathrm{C}$. This difference was eliminated in the trained sample when the TC constraint was raised to $40.1^{\circ} \mathrm{C}$ and the authors suggested adjusting the TC constraint to a more appropriate value for trained individuals. ${ }^{24} \mathrm{We}$ propose that more appropriate upper TC and HR PSI constraints than $39.5^{\circ} \mathrm{C}$ and 180 beats $\cdot \min ^{-1}$ are required to: $\left.i\right)$ ensure a PSI of 10 represents maximal physiological heat strain 
(i.e. maximal TC and HR) and; ii) avoid violating the 0-10 scale. Therefore, the aim of the current study was to determine if the PSI, in original or modified form, could quantify strain on a $0-10$ scale in trained and heat acclimatized men undertaking a competitive $21.1 \mathrm{~km}$ outdoor run in heat. Our first objective was to employ the PSI with original TC and HR upper constraints (i.e. $39.5^{\circ} \mathrm{C} \& 180 \mathrm{~b} \cdot \mathrm{min}^{-1}$ ). Our second objective was to investigate the influence of employing higher PSI TC constraints more appropriate to the higher TC responses produced by trained individuals (i.e. $40.0,40.5^{\circ} \mathrm{C} \& 41.0^{\circ} \mathrm{C}$ ) and a $\mathrm{HR}$ constraint based on the individual's age-predicted maximal HR. ${ }^{20}$

\section{Methods}

\section{Participants and Design}

The database from the observational study of Lee et al. ${ }^{25}$ was used in this study for retrospective analysis. This represented the physiological responses of 31 trained and heat acclimatized males participating in a $21.1 \mathrm{~km}$ mass-participation road-running race. They were heat acclimatized due to their prolonged military training in a warm-humid environment. Participants were volunteers and provided written informed consent to participate in the study. The study was approved by the Institutional Review Board and conformed to the standards set by the Declaration of Helsinki. Twenty-four of the 31 participants had complete TC and HR datasets and were included in this study (mean \pm SD age: $26 \pm 3 \mathrm{y}$; body mass: $65.5 \pm 6.5 \mathrm{~kg}$; height: $1.72 \pm 0.05 \mathrm{~m}$; $\mathrm{VO}_{2 \text { peak: }} 59 \pm 5(51-68) \mathrm{ml} \cdot \mathrm{kg} \cdot \mathrm{min}^{-1}$.

\section{Methodology}

Four weeks prior to the race, each individual performed an incremental treadmill test to volitional exhaustion for the determination of $\mathrm{VO}_{2 \text { peak }}$ and maximal $\mathrm{HR}$. On race day, the 21.1 $\mathrm{km}$ mass-participation event started at 0545 hours on a flat course at sea-level. TC and HR were measured at $15 \mathrm{~s}$ intervals throughout the race and averaged over one-minute intervals. HR was measured by a telemetry system (Polar Vantage, Polar EleTCtro Oy, Kempele, Finland). Ingestible telemetric temperature sensors and ambulatory data recorders measured gastro-intestinal temperature as an index of TC using CorTemp ${ }^{\mathrm{TM}}$ (HQ Inc., Palmetto, Florida, USA) and VitalSense ${ }^{\circledR}$ (Phillips Respironics, Bend, Oregon, USA) systems. ${ }^{26}$ Pre-race resting TC and HR values were obtained during a five minute period of seated rest. Measures of prerace hydration status (including urine specific gravity) and fluid balance were assessed as previously described. ${ }^{25}$ Environmental conditions were measured throughout the race. Heat balance parameters and the heat stress index (i.e. ratio of required evaporative cooling to maximum evaporative capacity of the environment) were estimated using the methods described by Brotherhood. ${ }^{27}$ Heat strain was quantified by four PSI methods and categorized according to Table 1. 
The original PSI with TC and HR constraints of $39.5^{\circ} \mathrm{C}$ and $180 \mathrm{~b} \cdot \mathrm{min}^{-1}$ (i.e. $\mathrm{PSI}_{39.5 / 180)}$ ), respectively, was computed at one-minute intervals as follows (Equation 1):

$$
\mathrm{PSI}_{39.5 / 180}=5\left(\mathrm{TC}_{\mathrm{t}}-\mathrm{TC}_{0}\right) \div\left(39.5-\mathrm{TC}_{0}\right)^{-1}+5\left(\mathrm{HR}_{\mathrm{t}}-\mathrm{HR}_{0}\right) \div\left(180-\mathrm{HR}_{0}\right)^{-1}
$$

where $\mathrm{TC}_{0}$ and $\mathrm{HR}_{0}$ are the pre-race measured resting $\mathrm{TC}$ and $\mathrm{HR}$, respectively; and $\mathrm{TC}_{\mathrm{t}}$ and $\mathrm{HR}_{\mathrm{t}}$ are simultaneous measurements taken at any time.

Modified PSI (PSI P0.0/PHRmax $, \mathrm{PSI}_{40.5 / \mathrm{PHR} \max }, \mathrm{PSI}_{41.0 / \mathrm{PHRmax}}$ ) the individual's age-predicted maximal HR and graded TC constraints of $40.0^{\circ} \mathrm{C}$ (Equation 2), $40.5^{\circ} \mathrm{C}$ (Equation 3), and $41.0^{\circ} \mathrm{C}$ (Equation 4). PSI was computed at one-minute intervals as follows:

$$
\begin{aligned}
& \mathrm{PSI}_{40.0 / \mathrm{PHRmax}}=5\left(\mathrm{TC}_{\mathrm{t}}-\mathrm{TC}_{0}\right) \div\left(40.0-\mathrm{TC}_{0}\right)^{-1}+5\left(\mathrm{HR}_{\mathrm{t}}-\mathrm{HR}_{0}\right) \div\left(\mathrm{PHRmax}-\mathrm{HR}_{0}\right)^{-1} \\
& \mathrm{PSI}_{40.5 / \mathrm{PHRmax}}=5\left(\mathrm{TC}_{\mathrm{t}}-\mathrm{TC}_{0}\right) \div\left(40.5-\mathrm{TC}_{0}\right)^{-1}+5\left(\mathrm{HR}_{\mathrm{t}}-\mathrm{HR}_{0}\right) \div\left(\mathrm{PHRmax}-\mathrm{HR}_{0}\right)^{-1} \\
& \mathrm{PSI}_{41.0 / \mathrm{PHRmax}}=5\left(\mathrm{TC}_{\mathrm{t}}-\mathrm{TC}_{0}\right) \div\left(41.0-\mathrm{TC}_{0}\right)^{-1}+5\left(\mathrm{HR}_{\mathrm{t}}-\mathrm{HR}_{0}\right) \div\left(\mathrm{PHRmax}-\mathrm{HR}_{0}\right)^{-1}
\end{aligned}
$$

where $\mathrm{TC}_{0}$ and $\mathrm{HR}_{0}$ are the pre-race measured resting $\mathrm{TC}$ and $\mathrm{HR}$, respectively; $\mathrm{TC}_{\mathrm{t}}$ and $\mathrm{HR}_{\mathrm{t}}$ are simultaneous measurements taken at any time; and PHRmax is the age-predicted maximal HR using the Nes et al. ${ }^{20}$ formula: PHRmax $\left(b \cdot \min ^{-1}\right)=211-0.64 \times$ Age.

\section{Statistical Analysis}

Data were analysed with IBM SPSS Statistics 24 and statistical significance was accepted as $P$ $<0.05$. Descriptive data are presented as mean $\pm \mathrm{SD}$ and range. A paired-sample t-test compared means for measured and age-predicted maximal HR. Single-factor (Time (7): minutes $15,30,45,60,75,90$, \& final) repeated measures ANOVA investigated changes in TC and HR over time. Two-factor (Time (7) x PSI method (4)) repeated measures ANOVA compared PSI method (i.e. PSI ${ }_{39.5 / 180}$, PSI $_{40.0 / P H R m a x}, \mathrm{PSI}_{40.5 / \mathrm{PHRmax}}$, and PSI $\mathrm{P}_{41.0 / \mathrm{PHR} \max }$ ) over time for total PSI, PSI TC component, PSI HR component, and percent TC and HR contribution to total PSI. Bonferroni follow-up tests were employed with adjustments for multiple comparisons. Mean differences are presented with 95\% confidence intervals (95\% CI). The standardized mean difference effect size (Cohen's $d$ ) was calculated and interpreted as: trivial $(<0.2)$; small $(\geq 0.2)$; medium $(\geq 0.5)$; and large $(\geq 0.8)$. Multiple regression analyses were conducted to determine the significant predictors of final and peak PSI $\mathrm{PL}_{410 / \mathrm{PHRmax}}$. The dependent variables considered related to endurance parameters (e.g. $\mathrm{VO}_{2 \text { peak }} \% \mathrm{VO}_{2 \text { peak }}$ ), anthropometry (e.g. body mass, body surface area, \% fat), hydration status and fluid balance (e.g. pre-race urine specific gravity, fluid intake, \% dehydration), and heat production (e.g. W, $\mathrm{W} \cdot \mathrm{kg}^{-1}, \mathrm{~W} \cdot \mathrm{m}^{2}$ ). A stepwise forward entry method was used based on entry of the dependent variable correlating highest with the independent variable, followed by the highest correlate with the standardized residual variance, until there were no significant correlates with the residual variance. 
Environmental conditions varied minimally throughout the race, being warm (dry bulb temperature $=26.1-27.3 \mathrm{C}^{\circ}$ ), humid (relative humidity $=79-82 \%$ ), and calm (air velocity $=0.0$ $1.1 \mathrm{~m} \cdot \mathrm{s}^{-1}$ ). The heat stress index (HSI) indicated a physiologically compensable environment $(\mathrm{HSI}=0.82 \pm 0.08(0.65-0.97))$. All 24 participants completed the race asymptomatic and their performance and physiological responses are illustrated in Table 2.

$* * * *$ Insert Table 2 Here $* * * *$

\section{Core Temperature \& Heart Rate Responses}

Fig 1 illustrates the continuous individual TC and HR responses and Table 2 illustrates mean, peak values, and final values. For peak TC, $63 \%$ of runners recorded TC $>39.5^{\circ} \mathrm{C}, 33 \%$ $>40.0^{\circ} \mathrm{C}, 8 \%>40.5^{\circ} \mathrm{C}$, and $0 \%>41.0^{\circ} \mathrm{C}$. For peak HR, $71 \%$ of runners recorded HR $>180$ $\mathrm{b} \cdot \mathrm{min}^{-1}$. Fifty percent of runners exceeded both $39.5^{\circ} \mathrm{C}$ and $180 \mathrm{~b} \cdot \mathrm{min}^{-1}$. Significant increases in TC were observed at 30-, 75-, and 90-min $(P \leq 0.024)$; HR increased significantly from $15-$ min only at the final minute $(P=0.006)$. HR drift from 15 -min $\left(172 \pm 8 \mathrm{~b} \cdot \mathrm{min}^{-1}\right)$ to 90 -min $\left(177 \pm 9 \mathrm{~b} \cdot \mathrm{min}^{-1}\right)$ was $5.3(1.4,11.9) \mathrm{b} \cdot \mathrm{min}^{-1}(P=0.294, d=0.59)$ or $3.1 \%$. Measured maximal HR $\left(193 \pm 7 \mathrm{~b} \cdot \mathrm{min}^{-1}\right)$ was not significantly different from the age-predicted estimate $(195 \pm 2$ $\mathrm{b} \cdot \mathrm{min}^{-1}$; mean difference $\left.=-1.5(-4.3,1.3) \mathrm{b} \cdot \mathrm{min}^{-1}, P=0.225, d=0.30\right)$ employed in the three modified PSI equations. Two runners exceeded their age-predicted maximal HR by 1 and 2 $\mathrm{b} \cdot \mathrm{min}^{-1}$ during the race.

\section{Total PSI}

Fig 2A-D illustrate the continuous individual PSI responses according to the four PSI methods.

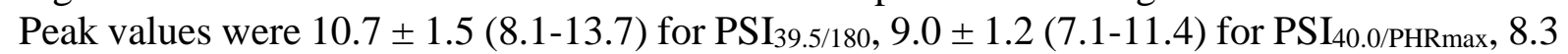

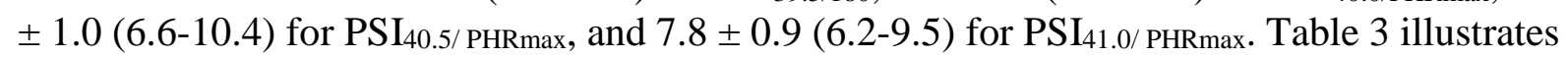
that final PSI was significantly greater with PSI $_{39.5 / 180}$ than all other methods $(P \leq 0.001)$ with large effect sizes and also significantly greater with $\mathrm{PSI}_{40.0 / P H R m a x}$ than $\mathrm{PSI}_{41.0 / \mathrm{PHRmax}}$ (mean difference $=1.2(0.4,2.0)$ units, $P=0.037, d=0.91)$. Fig 3A illustrates that heat strain throughout the race with $\mathrm{PSI}_{39.5 / 180}$ was significantly greater than all other methods $(P<0.003)$ and heat strain with PSI $40.0 /$ PHRmax was significantly greater than $\mathrm{PSI}_{41.0 / \mathrm{PHRmax}}(P<0.001)$. Fig 4A-D illustrate that PSI $_{39.5 / 180}$ categorized the majority (63\%) of runners as experiencing heat strain >10, whereas $\mathrm{PSI}_{40.0 / \mathrm{PHRmax}}(50 \%)$, $\mathrm{PSI}_{40.5 / \mathrm{PHR} \max }(63 \%)$, and $\mathrm{PSI}_{41.0 / \mathrm{PHR} \max }(75 \%)$ categorized the majority of runners as experiencing high (i.e. $\geq 7<9$ ) heat strain. PSI $_{40.0 / P H R m a x}$ and $\mathrm{PSI}_{40.5 / \mathrm{PHRmax}}$ categorized $25 \%$ and $8 \%$ of runners as experiencing heat strain $>10$,

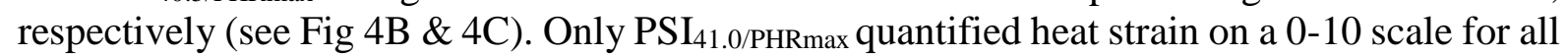
runners (see Fig 4D). Table 4 illustrates that a two-component multiple regression model (i.e. mean speed and pre-race urine specific gravity) explained $57 \%$ of the variation in final 
$\mathrm{PSI}_{41.0 / \mathrm{PHRmax}}$ and a single-component model (i.e. mean speed) explained $17 \%$ of the variance in peak PSI $_{41.0 / P H R m a x}$.

\section{PSI TC Component}

The PSI TC component exceeded 5.0 in $63 \%$ of runners when quantified by $\mathrm{PSI}_{39.5 / 180}, 33 \%$

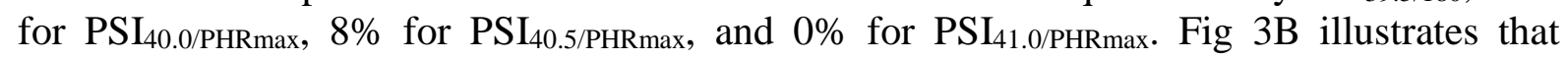
$\mathrm{PSI}_{39.5 / 180}$ TC was significantly greater than all other methods during the race $(P<0.003)$ and $\mathrm{PSI}_{40.0 / \mathrm{PHRmax}}$ was significantly greater than $\mathrm{PSI}_{40.5 / \mathrm{PHRmax}}$ and $\mathrm{PSI}_{41.0 / \mathrm{PHRmax}}$ (both $P<0.001$ ). Table 3 illustrates that final PSI TC was significantly greater with PSI $_{39.5 / 180}$ than all other methods $(P \leq 0.001)$ with moderate-to-large large effect sizes and also significantly greater with PSI PI.0/PHRmax $_{\text {than }}$ PSI $_{41.0 / \text { PHRmax }}$ (mean difference $=1.2(0.6,1.9)$ units, $P=0.007, d=$ 1.07). The mean relative contribution of the TC component to total PSI differed significantly between all methods $(P<0.001)$ : PSI $_{39.5 / 180}\left(39.8\right.$ (38.0, 41.6) \%), PSI $_{40.0 / P H R m a x}(37.7$ (35.9, $39.4) \%)$, PSI $_{40.5 / \text { PHRmax }}(34.0(32.4,35.7) \%)$, and PSI $41.0 /$ PHRmax $(31.2(29.6,32.9) \%)$.

\section{PSI HR Component}

The PSI HR component exceeded 5.0 in $75 \%$ of runners when quantified by $\mathrm{PSI}_{39.5 / 180}$ and $8 \%$ for the three PSI methods employing the age-predicted maximal HR constraint. Fig 3C illustrates that $\mathrm{PSI}_{39.5 / 180} \mathrm{HR}$ component was significantly greater than all other methods during the race $(P<0.003)$. Table 3 illustrates that final PSI HR was significantly greater with PSI $_{39.5 / 180}$ than all other methods $(P \leq 0.001)$ with large effect sizes. The mean relative contribution of the HR component to total PSI differed significantly between all methods $(P<$ 0.001): PSI $_{39.5 / 180}(60.2(58.4,62.0) \%)$, PSI $_{40.0 / P H R m a x}(62.3(60.6,64.1) \%), \mathrm{PSI}_{40.5 / \mathrm{PHRmax}}(66.0$ $(64.3,67.6) \%)$, and $\mathrm{PSI}_{41.0 / \mathrm{PHR} \max }(69.0(67.4,70.6) \%)$. The relative contribution of HR to total PSI was significantly higher than the TC contribution until equivalence was reached at 75-min for $\mathrm{PSI}_{39.5 / 180}(P \leq 0.015)$, at the final minute for $\mathrm{PSI}_{40.0 / P H R \max }(P \leq 0.015)$, and throughout the race for $\mathrm{PSI}_{40.5 / \mathrm{PHRmax}}(P \leq 0.001)$ and $\mathrm{PSI}_{41.0 / \mathrm{PHRmax}}(P \leq 0.001)$.

$$
\begin{aligned}
& * * * * \text { Insert Figure } 3 \text { Here } * * * * \\
& * * * * \text { Insert Figure } 4 \text { Here } * * * * \\
& * * * * \text { Insert Table } 3 \text { Here } * * * * \\
& * * * * \text { Insert Table } 4 \text { Here } * * * *
\end{aligned}
$$


The main finding of this study is that only when the PSI upper TC and HR constraints are modified (to $41.0^{\circ} \mathrm{C}$ and age-predicted maximal HR, respectively), does PSI quantify heat strain on a 0-10 scale for trained and heat acclimatized men undertaking competitive endurance exercise in outdoor heat. The original PSI constraints of TC $39.5^{\circ} \mathrm{C}$ and HR $180 \mathrm{~b} \cdot \mathrm{min}^{-1}$ were demonstrated as too low for this population, since almost two-thirds of our sample exceeded $39.5^{\circ} \mathrm{C}$, nearly three-quarters exceeded $180 \mathrm{~b} \cdot \mathrm{min}^{-1}$, and half the sample exceeded both. This resulted in $63 \%$ of the sample exhibiting heat strain that exceeded the $0-10$ scale. Substituting the HR constraint of $180 \mathrm{~b} \cdot \mathrm{min}^{-1}$ for age-predicted maximal HR and employing higher fixed TC constraints, considered more relevant to a trained and heat acclimatized population, reduced or eliminated the proportion of individuals exceeding the 0-10 scale (i.e. $25 \%$ with PSI $_{40.0 / \text { PHRmax }}, 8 \%$ with PSI $40.5 /$ PHRmax, and $0 \%$ with PSI $\left._{41.0 / P H R m a x}\right)$.

The use of predicted or measured maximal HR as the upper PSI HR constraint is a logical and simple solution to the problem of individuals exceeding an arbitrary fixed value. We employed age-predicted maximal HR as we wished to test readily available PSI equations requiring no prior physiological testing. We observed no difference between measured and predicted maximal HR using the Nes et al. ${ }^{20}$ formula (mean difference $=-1.5(-4.3,1.3) \mathrm{b} \cdot \mathrm{min}^{-}$ ${ }^{1}, P=0.225, d=0.30$ ), with only two runners exceeding the age-predicted maximal HR during the race by $1-2 \mathrm{~b} \cdot \mathrm{min}^{-1}$. Furthermore, a comparison of the PSI HR component calculated with measured and predicted maximal HR revealed no differences in mean PSI HR (mean difference $=-0.04(-0.18,0.09)$ units, $P=1.0, d=0.09)$. Employing measured maximal HR may offer marginally greater sensitivity of the PSI, since the between-subject variability in maximal HR at a given age is approximately $7-11 \mathrm{~b} \cdot \mathrm{min}^{-1},{ }^{19}$ whereas the within-subject variability in measured maximal HR is typically $3 \mathrm{~b} \cdot \mathrm{min}^{-1}{ }^{28}$ Previous laboratory studies have computed PSI with measured maximal HR as the upper HR constraint to overcome the issue of individuals exceeding the $180 \mathrm{~b} \cdot \mathrm{min}^{-1}$ limit. ${ }^{24,29}$ Whilst the use of age-predicted maximal HR is a superior approach to the arbitrary $180 \mathrm{~b} \cdot \mathrm{min}^{-1}$ constraint, when available, the measured maximal HR should be employed as the upper HR constraint to provide greater individualisation of the PSI.

The mean relative exercise intensity (\%HRmax) observed in the current study was 90 $\pm 3 \%$, which is remarkably consistent with previous observations of HR during competitive $21-\mathrm{km}$ running in cooler environments, such as $91 \pm 1 \%,{ }^{30} 89 \pm 3 \%,{ }^{30}$ and $91 \% .{ }^{21}$ Heart rate was consistent throughout the race with a significant increase from 15-min only observed in the final minute of the race. Estimated cardiovascular drift from 15- to 90-min was minimal (i.e. $5 \mathrm{~b} \cdot \mathrm{min}^{-1}$ or $3 \%$ ) and would be predicted to reduce stroke volume by $2-3 \%$ and $\mathrm{VO}_{2 \text { peak }}$ by $5-6 \% .{ }^{23}$ Our runners exhibited a reverse $\mathrm{J}$-shaped pacing profile, characterised by an early slowing of pace and final end-spurt, ${ }^{25}$ which is typical of self-paced performance in heat. ${ }^{1}$ Such a strategy appears to have been successful in minimising cardiovascular drift and maintaining a cardiovascular reserve. ${ }^{23}$

The use of a fixed upper PSI TC constraint is appealing as it has practical value that would enable standardised comparisons within or between participants in a sport or between participants across sports. The original constraint of $39.5^{\circ} \mathrm{C}$ was demonstrated as too low for trained and heat acclimatized individuals competing in heat since we observed $63 \%$ of individuals exceeding this limit. In a laboratory study, Tikuisis et al. ${ }^{24}$ reported that physiological and perceptual strain were better aligned in trained individuals when the upper PSI TC constraint was $40.1^{\circ} \mathrm{C}$ rather than $39.5^{\circ} \mathrm{C}$. However, our data suggest that a $40.0^{\circ} \mathrm{C}$ limit is also too low for the trained and heat acclimatized population since one-third exceeded this limit. This is supported by similar studies of $8-\mathrm{km}$ and $21-\mathrm{km}$ running in heat, where peak 
TC $>40.0^{\circ} \mathrm{C}$ was observed in $82 \%^{7}$ and $50 \%^{6}$ of the study samples, respectively. Evidence also suggests that trained individuals exceed $\mathrm{TC} 39.5^{\circ} \mathrm{C}$ and $40.0^{\circ} \mathrm{C}$ when competing in cycling, ${ }^{9}$ football codes ${ }^{8,12,13}$, and tennis. ${ }^{14}$ In our study, applying TC constraints of $40.5^{\circ} \mathrm{C}$ and $41.0^{\circ} \mathrm{C}$ produced TC component and total PSI values that were not significantly different from each other (see Table $4 \&$ Fig $3 \mathrm{~A} \& \mathrm{~B}$ ) and the categorisation of heat strain between the two methods was not meaningfully altered (see Fig 4C\&D). Although, the constraint of $40.5^{\circ} \mathrm{C}$ was exceeded by only $8 \%(2 / 24)$ of runners, it was only by applying a TC constraint of $41.0^{\circ} \mathrm{C}$ that we could accommodate all $\mathrm{TC}$ responses. A $41.0^{\circ} \mathrm{C}$ TC constraint would accommodate the recently reported range of peak TC values for trained individuals undertaking an 8-km track running race $\left(39.7-40.9^{\circ} \mathrm{C}\right)$ and a $40.3-\mathrm{km}$ cycling time trial $\left(39.6-41.0^{\circ} \mathrm{C}\right){ }^{7,9}$ However, not all TC responses would be accommodated since observations of $\mathrm{TC}>41.0^{\circ} \mathrm{C}$ in asymptomatic distance runners are observed, albeit infrequently. ${ }^{6,31-34} \mathrm{With}$ the minimal lethal $\mathrm{TC}$ for humans being approximately $42{ }^{\circ} \mathrm{C},{ }^{1}$ a TC constraint of $41^{\circ} \mathrm{C}$ strikes a balance between capturing the majority of TC responses and maintaining a safety threshold. Therefore, for future use of PSI with trained and heat acclimatized individuals, we recommend employing an upper TC constraint of $41^{\circ} \mathrm{C}$.

Mean speed $\left(\Delta R^{2}=.48\right)$ and pre-race urine specific gravity $\left(\Delta R^{2}=.13\right)$ were identified as significant predictors of final PSI I1.0/PHRmax $_{1}$ explaining $57 \%$ of the variance. Running speed has frequently been observed to correlate positively with final TC in field studies ${ }^{35,36}$ and our findings extend this relationship to PSI. Running speed was positively associated with both final PSI TC $\left(R^{2}=.45, P<0.001\right)$ and HR components $\left(R^{2}=.28, P=0.008\right)$. Cramer and Jay ${ }^{16}$ recently demonstrated that heat production in $\mathrm{W} \cdot \mathrm{kg}^{-1}$ was the single best predictor of $\triangle \mathrm{TC}$ during 60 min of laboratory cycling, explaining $50 \%$ of the variance. We suggest that mean speed in the current study represents the best surrogate measure of metabolic heat production. Mean speed was most strongly and positively associated with predicted mean heat production expressed in $\mathrm{W} \cdot \mathrm{kg}^{-1}\left(R^{2}=.72, P<0.001\right)$ and predicted heat production in $\mathrm{W} \cdot \mathrm{kg}^{-1}$ was also positively associated with peak $\left(R^{2}=.20, P=0.028\right)$ and final $\mathrm{PSI}_{41.0 / \mathrm{PHRmax}}\left(R^{2}=.31, P=\right.$ $0.005)$. Pre-exercise urine specific gravity, as a measure of hydration status, was also positively associated with both final PSI TC $\left(R^{2}=.21, P=0.025\right)$ and HR components $\left(R^{2}=.41, P=\right.$ $0.001)$ and independently explained $13 \%$ of the variance in final PSI $41.0 /$ PHRmax. Armstrong et al. ${ }^{37}$ reported that a urine specific gravity in the range 1.018-1.020 represents euhydration and our values ranged from 1.001-1.025. Our findings provide general support to the concept that PSI is sensitive to pre-exercise hydration status. ${ }^{5}$

\section{Practical Applications}

The PSI is a simple tool requiring the simultaneous measurements of HR and TC to provide a heat strain rating on a 0-10 scale, which can be employed by the sports physiologist in the field. Simple modifications to the upper TC and HR constraints (i.e. $41.0^{\circ} \mathrm{C}$ and agepredicted or measured maximal HR) will increase the utility of the PSI for trained and heat acclimatized individuals. The index should prove valuable in providing objective evidence of heat adaptation and the effectiveness of heat strain mitigation interventions (i.e. reduced PSI during constant load exercise), and the magnitude of heat strain experienced during training and competition in environmental heat. The participants in this study were naturally heat acclimatized as a result of their prolonged military training in a warm-humid environment and our findings are generalizable to individuals with prolonged heat acclimatization and thermal tolerance status. Our study data should prove useful in providing comparative data for such individuals undertaking competitive endurance exercise in natural environmental heat. 
Consideration should be given to appropriate PSI constraints for non-endurance trained and non-heat acclimatized populations. Tikuisis et al. ${ }^{24}$ observed that physiological and perceptual strain were aligned in untrained and unacclimatized individuals with constraints of $39.5^{\circ} \mathrm{C} /$ maximal $\mathrm{HR}$ and $40.1^{\circ} \mathrm{C} /$ maximal $\mathrm{HR}$ for trained and unacclimatized individuals. We support the use of these constraints for the specific populations and recommend the $40.5^{\circ} \mathrm{C}$ and $41.0^{\circ} \mathrm{C}$ constraints are reserved for the endurance trained and fully heat acclimatized individuals. Consideration of the training and heat acclimatization status of the individual by the sports physiologist and sports medicine practitioner should inform selection of appropriate PSI constraints

Future research and practice may wish to establish individualised PSI equations based on an individual's measured maximal HR and a maximal TC established during a competitive effort. The between-subject variability in TC response to self-paced exercise is typically large (e.g. peak TC $38.2-40.7^{\circ} \mathrm{C}$ in current study), variability remains even in highly controlled settings, ${ }^{15,16}$ and therefore a within-subject approach would be expected to increase the sensitivity of the PSI. A high skin temperature in combination with a high TC impairs aerobic exercise performance in heat ${ }^{38}$ and therefore future physiological heat strain indices should investigate the incorporation of skin temperature.

\section{Study Limitations}

We acknowledge that the alternative to applying different TC and HR constraints based on the population under study is to apply the original $39.5^{\circ} \mathrm{C} / 180$ beats $\cdot \mathrm{min}^{-1}$ constraints and interpret the heat strain output differently for specific populations. However, as demonstrated in the current study, this will likely result in a large proportion of PSI responses exceeding the value of 10. We believe the simple 0-10 scale is a major strength of PSI and this feature should be retained by simple modification of PSI constraints based on the population under study.

\section{Conclusions}

The physiological strain index was able to quantify heat strain on a $0-10$ scale in trained and heat acclimatized men undertaking a competitive half-marathon running race in heat, but only when the upper TC and HR constraints were modified to $41.0^{\circ} \mathrm{C}$ and age-predicted maximal $\mathrm{HR}$, respectively. We recommend simple modifications to the upper TC and HR constraints (i.e. $41.0^{\circ} \mathrm{C}$ and age-predicted or measured maximal $\mathrm{HR}$ value) to increase the utility of this heat strain index for trained and heat acclimatized individuals.

\section{Conflict of Interest}

None declared. 


\section{References}

1. Sawka MN, Leon LR, Montain SJ, Sonna LA. Integrated physiological mechanisms of exercise performance, adaptation, and maladaptation to heat stress. Compr Physiol. 2011;1(4):18831928.

2. Moran DS, Shitzer A, Pandolf KB. A physiological strain index to evaluate heat stress. Am J Physiol. 1998;275(1 Pt 2):R129-134.

3. Moran DS. Stress evaluation by the physiological strain index (PSI). J Basic Clin Physiol Pharmacol. 2000;11(4):403-423.

4. Moran DS, Kenney WL, Pierzga JM, Pandolf KB. Aging and assessment of physiological strain during exercise-heat stress. Am J Physiol Regul Integr Comp Physiol. 2002;282(4):R1063-1069.

5. Moran DS, Montain SJ, Pandolf KB. Evaluation of different levels of hydration using a new physiological strain index. Am J Physiol. 1998;275(3 Pt 2):R854-860.

6. Byrne C, Lee JK, Chew SA, Lim CL, Tan EY. Continuous thermoregulatory responses to massparticipation distance running in heat. Med Sci Sports Exerc. 2006;38(5):803-810.

7. Ely BR, Ely MR, Cheuvront SN, Kenefick RW, Degroot DW, Montain SJ. Evidence against a 40 degrees $C$ core temperature threshold for fatigue in humans. J Appl Physiol (1985). 2009;107(5):1519-1525.

8. Mohr M, Nybo L, Grantham J, Racinais S. Physiological responses and physical performance during football in the heat. PLoS One. 2012;7(6):e39202.

9. Racinais S, Periard JD, Karlsen A, Nybo L. Effect of heat and heat acclimatization on cycling time trial performance and pacing. Med Sci Sports Exerc. 2015;47(3):601-606.

10. Lucia A, Hoyos J, Santalla A, Earnest C, Chicharro JL. Tour de France versus Vuelta a Espana: which is harder? Med Sci Sports Exerc. 2003;35(5):872-878.

11. Veltmeijer MT, Eijsvogels TM, Thijssen DH, Hopman MT. Incidence and predictors of exertional hyperthermia after a 15-km road race in cool environmental conditions. J Sci Med Sport. 2015;18(3):333-337.

12. DeMartini JK, Martschinske JL, Casa DJ, et al. Physical demands of National Collegiate Athletic Association Division I football players during preseason training in the heat. J Strength Cond Res. 2011;25(11):2935-2943.

13. Aughey RJ, Goodman CA, McKenna MJ. Greater chance of high core temperatures with modified pacing strategy during team sport in the heat. J Sci Med Sport. 2014;17(1):113-118.

14. Periard JD, Racinais S, Knez WL, Herrera CP, Christian RJ, Girard O. Thermal, physiological and perceptual strain mediate alterations in match-play tennis under heat stress. Br J Sports Med. 2014;48 Suppl 1:i32-i38.

15. Jay O, Bain AR, Deren TM, Sacheli M, Cramer MN. Large differences in peak oxygen uptake do not independently alter changes in core temperature and sweating during exercise. Am J Physiol Regul Integr Comp Physiol. 2011;301(3):R832-841.

16. Cramer MN, Jay O. Explained variance in the thermoregulatory responses to exercise: the independent roles of biophysical and fitness/fatness-related factors. J Appl Physiol (1985). 2015;119(9):982-989.

17. Selkirk GA, McLellan TM. Influence of aerobic fitness and body fatness on tolerance to uncompensable heat stress. J Appl Physiol (1985). 2001;91(5):2055-2063.

18. Selkirk GA, McLellan TM, Wright HE, Rhind SG. Mild endotoxemia, NF-kappaB translocation, and cytokine increase during exertional heat stress in trained and untrained individuals. $A m \mathrm{~J}$ Physiol Regul Integr Comp Physiol. 2008;295(2):R611-623.

19. Tanaka H, Monahan KD, Seals DR. Age-predicted maximal heart rate revisited. J Am Coll Cardiol. 2001;37(1):153-156.

20. Nes BM, Janszky I, Wisloff U, Stoylen A, Karlsen T. Age-predicted maximal heart rate in healthy subjects: The HUNT fitness study. Scand J Med Sci Sports. 2013;23(6):697-704.

21. Esteve-Lanao J, Lucia A, deKoning JJ, Foster C. How do humans control physiological strain during strenuous endurance exercise? PLoS One. 2008;3(8):e2943. 
22. Hornery DJ, Farrow D, Mujika I, Young W. An integrated physiological and performance profile of professional tennis. Br J Sports Med. 2007;41(8):531-536; discussion 536.

23. Wingo JE, Ganio MS, Cureton KJ. Cardiovascular drift during heat stress: implications for exercise prescription. Exercise and sport sciences reviews. 2012;40(2):88-94.

24. Tikuisis $P, M c L e l l a n T M$, Selkirk $G$. Perceptual versus physiological heat strain during exerciseheat stress. Med Sci Sports Exerc. 2002;34(9):1454-1461.

25. Lee JK, Nio AQ, Lim CL, Teo EY, Byrne C. Thermoregulation, pacing and fluid balance during mass participation distance running in a warm and humid environment. Eur J Appl Physiol. 2010;109(5):887-898.

26. Byrne C, Lim CL. The ingestible telemetric body core temperature sensor: a review of validity and exercise applications. Br J Sports Med. 2007;41(3):126-133.

27. Brotherhood JR. Heat stress--a challenge for sports science in Australia. J Sci Med Sport. 2008;11(1):1-2.

28. Achten J, Jeukendrup AE. Heart rate monitoring: applications and limitations. Sports Med. 2003;33(7):517-538.

29. Schlader ZJ, Raman A, Morton RH, Stannard SR, Mundel T. Exercise modality modulates body temperature regulation during exercise in uncompensable heat stress. Eur J Appl Physiol. 2011;111(5):757-766.

30. Selley EA, Kolbe T, Van Zyl CG, Noakes TD, Lambert MI. Running intensity as determined by heart rate is the same in fast and slow runners in both the 10- and 21-km races. J Sports Sci. 1995;13(5):405-410.

31. Robinson S. TEMPERATURE REGULATION IN EXERCISE. Pediatrics. 1963;32:Suppl 691-702.

32. Pugh LG, Corbett JL, Johnson RH. Rectal temperatures, weight losses, and sweat rates in marathon running. Journal of applied physiology. 1967;23(3):347-352.

33. Wyndham $\mathrm{CH}$, Strydom NB. The danger of an inadequate water intake during marathon running. South African medical journal = Suid-Afrikaanse tydskrif vir geneeskunde. 1969;43(29):893-896.

34. Maron MB, Wagner JA, Horvath SM. Thermoregulatory responses during competitive marathon running. Journal of applied physiology: respiratory, environmental and exercise physiology. 1977;42(6):909-914.

35. Maughan RJ, Leiper JB, Thompson J. Rectal temperature after marathon running. Br J Sports Med. 1985;19(4):192-195.

36. Noakes TD, Myburgh KH, du Plessis J, et al. Metabolic rate, not percent dehydration, predicts rectal temperature in marathon runners. Med Sci Sports Exerc. 1991;23(4):443-449.

37. Armstrong LE, Pumerantz AC, Fiala KA, et al. Human hydration indices: acute and longitudinal reference values. International journal of sport nutrition and exercise metabolism. 2010;20(2):145-153.

38. Cheuvront SN, Kenefick RW, Montain SJ, Sawka MN. Mechanisms of aerobic performance impairment with heat stress and dehydration. J Appl Physiol (1985). 2010;109(6):1989-1995. 
Table 1: Evaluation and categorization of heat strain by PSI.

\begin{tabular}{|c|c|}
\hline PSI & Strain \\
\hline 0 & No to little \\
1 & Low \\
2 & \\
3 & Moderate \\
4 & \\
5 & High \\
6 & \\
7 & Very high \\
8 & Maximal \\
9 & \\
10 & \\
\hline
\end{tabular}

Adapted from Moran et al. ${ }^{2}$ to indicate a PSI of 10 represents maximal physiological strain i.e. attainment of maximal heart rate and maximal delineated core temperature for the population under study. 
Table 2: Summary of the physiological responses to the $21-\mathrm{km}$ race.

\begin{tabular}{|c|c|c|}
\hline & Mean \pm SD & Range \\
\hline Pre-race urine specific gravity (units) & $1.013 \pm 0.007$ & $1.001-1.025$ \\
\hline Mean speed $\left(\mathrm{km} \cdot \mathrm{h}^{-1}\right)$ & $11.7 \pm 1.0$ & $9.1-13.7$ \\
\hline Mean TC $\left({ }^{\circ} \mathrm{C}\right)$ & $39.0 \pm 0.3$ & $38.1-39.5$ \\
\hline Peak TC $\left({ }^{\circ} \mathrm{C}\right)$ & $39.7 \pm 0.5$ & $38.5-40.7$ \\
\hline Final TC $\left({ }^{\circ} \mathrm{C}\right)$ & $39.6 \pm 0.6$ & $38.2-40.7$ \\
\hline Mean HR $\left(b \cdot \min ^{-1}\right)$ & $173 \pm 7$ & $161-187$ \\
\hline Peak HR $\left(b \cdot \min ^{-1}\right)$ & $186 \pm 6$ & $175-196$ \\
\hline Final HR $\left(b \cdot \min ^{-1}\right)$ & $181 \pm 10$ & $159-195$ \\
\hline Mean \%HRmax & $90 \pm 3$ & $84-97$ \\
\hline Peak \%HRmax & $96 \pm 3$ & $90-100$ \\
\hline Final \%HRmax & $94 \pm 5$ & $83-100$ \\
\hline Mean $\mathrm{VO}_{2}\left(\mathrm{ml} \cdot \mathrm{kg} \cdot \mathrm{min}^{-1}\right)$ & $43 \pm 4$ & $35-49$ \\
\hline Mean $\% \mathrm{VO}_{2 \text { peak }}$ & $72 \pm 5$ & $59-80$ \\
\hline \multicolumn{3}{|l|}{ Mean heat production } \\
\hline $\mathrm{W}$ & $943 \pm 114$ & 739-1132 \\
\hline $\mathrm{W} \cdot \mathrm{m}^{2}$ & $531 \pm 52$ & $448-622$ \\
\hline $\mathrm{W} \cdot \mathrm{kg}^{-1}$ & $14.4 \pm 1.4$ & $12.2-16.9$ \\
\hline Fluid intake (L) & $0.29 \pm 0.21$ & $0-0.74$ \\
\hline Sweat loss (L) & $2.58 \pm 0.59$ & $1.54-4.40$ \\
\hline Sweat rate $\left(\mathrm{L} \cdot \mathrm{h}^{-1}\right)$ & $1.45 \pm 0.33$ & $0.85-2.28$ \\
\hline Body mass loss (kg) & $2.58 \pm 0.61$ & $1.73-4.46$ \\
\hline Dehydration (\%) & $3.93 \pm 0.80$ & $2.53-6.20$ \\
\hline
\end{tabular}


Table 3: Comparison of final values for PSI total score, PSI TC component, and PSI HR component across four PSI computational methods, and mean differences from PSI $_{39.5 / 180}$ for each modified PSI method.

\begin{tabular}{|c|c|c|c|c|}
\hline & Mean \pm SD (range) & Mean Difference $(95 \% \mathrm{CI})$ & $P$ value & Effect Size $(d)$ \\
\hline $\begin{array}{l}\text { PSI Total } \\
\text { PSI }_{39.5 / 180} \\
\text { PSI }_{40.0 / P H R m a x} \\
\text { PSI }_{40.5 / \text { PHRmax }} \\
\text { PSI }_{41.0 / \text { PHRmax }} \\
\end{array}$ & $\begin{array}{c}10.3 \pm 1.8(5.7-13.7) \\
8.8 \pm 1.5(4.9-11.4) \\
8.1 \pm 1.3(4.7-10.3) \\
7.6 \pm 1.1^{*}(4.5-9.5)\end{array}$ & $\begin{array}{l}1.6(0.4,2.7) \\
2.2(1.1,3.4) \\
2.8(1.6,3.9)\end{array}$ & $\begin{array}{l}0.002 \\
0.000 \\
0.000\end{array}$ & $\begin{array}{l}0.94 \\
1.41 \\
1.80\end{array}$ \\
\hline $\begin{array}{l}\text { PSI TC Component } \\
\text { PSI }_{39.5 / 180} \\
\text { PSI }_{40.0 / P H R m a x} \\
\text { PSI }_{40.5 / \text { PHRmax }} \\
\text { PSI }_{41.0 / \text { PHRmax }}\end{array}$ & $\begin{array}{l}5.3 \pm 1.6(1.6-8.2) \\
4.3 \pm 1.3(1.3-6.5) \\
3.6 \pm 1.0(1.1-5.4) \\
3.1 \pm 0.9^{\dagger}(0.9-4.6)\end{array}$ & $\begin{array}{l}1.0(0.1,2.0) \\
1.7(0.8,2.7) \\
2.2(1.3,3.1) \\
\end{array}$ & $\begin{array}{l}0.026 \\
0.000 \\
0.000 \\
\end{array}$ & $\begin{array}{l}0.73 \\
1.30 \\
1.72 \\
\end{array}$ \\
\hline $\begin{array}{l}\text { PSI HR Component } \\
\text { PSI }_{39.5 / 180} \\
\text { PSI }_{40.0 / P H R m a x} \\
\text { PSI }_{40.5 / \text { PHRmax }} \\
\text { PSI }_{41.0 / \text { PHRmax }}\end{array}$ & $\begin{array}{l}5.1 \pm 0.4(4.1-5.7) \\
4.5 \pm 0.4(3.6-5.0) \\
4.5 \pm 0.4(3.6-5.0) \\
4.5 \pm 0.4(3.6-5.0)\end{array}$ & $\begin{array}{l}0.5(0.2,0.7) \\
0.5(0.2,0.7) \\
0.5(0.2,0.7)\end{array}$ & $\begin{array}{l}0.000 \\
0.000 \\
0.000\end{array}$ & $\begin{array}{l}1.36 \\
1.36 \\
1.36\end{array}$ \\
\hline
\end{tabular}

Indicates mean is significantly less than $\mathrm{PSI}_{40.0 / \mathrm{PHRmax}},{ }^{*} P=0.037 ;{ }^{\dagger} \mathrm{P}=0.007$. 
Table 4: Multiple regression models for the prediction of final and peak PSI $_{41.0 / P H R m a x}$.

\begin{tabular}{|l|c|c|c|c|c|}
\hline & $B$ & $S E$ B & $\beta$ & $P$ value & $R^{2}$ \\
\hline Final PSI & & & & & \\
$\quad$ Constant & -62.56 & 23.43 & & & \\
$\quad$ Mean Speed $\left(\mathrm{km} \cdot \mathrm{h}^{-1}\right)$ & 0.62 & 0.16 & .57 & 0.001 & .48 \\
$\quad$ Pre-race urine specific gravity (units) & 62.06 & 23.69 & .38 & 0.016 & .13 \\
Adjusted $R^{2}$ & & & & & .57 \\
& & & & & \\
Peak PSI & & & & & \\
$\quad$ Constant & 3.20 & 1.97 & & & \\
$\quad$ Mean Speed $\left(\mathrm{km} \cdot \mathrm{h}^{-1}\right)$ & 0.39 & 0.17 & .45 & 0.028 & .20 \\
Adjusted $R^{2}$ & & & & & .17 \\
\hline
\end{tabular}

Pre USG, pre-race urine specific gravity. 


\section{Figure Captions}

Figure 1: Individual core temperature $(\mathbf{A})$ and heart rate $(\mathbf{B})$ responses to the race. Dashed lines illustrate the PSI TC constraints of $39.5,40.0,40.5$, and $41.0^{\circ} \mathrm{C}(\mathbf{A})$; the PSI HR constraint of $180 \mathrm{~b} \cdot \mathrm{min}^{-1}$, measured mean maximal HR of $193 \mathrm{~b} \cdot \mathrm{min}^{-1}$, and predicted mean maximal HR of $195 \mathrm{~b} \cdot \mathrm{min}^{-1}(\mathbf{B})$. For clarity, chart is truncated for two runners finishing $>120$-min (126- \& 137-min).

Figure 2: Individual PSI responses of the 24 participants to the $21.1 \mathrm{~km}$ race according to PSI

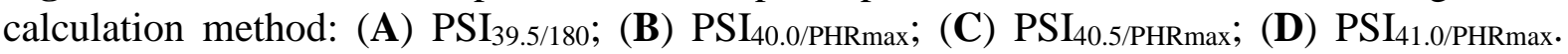
Dashed lines represent the theoretical maximal PSI rating of 10. For clarity, chart is truncated for two runners finishing >120-min (126- \& 137-min).

Figure 3: PSI total (A), PSI TC component (B), and PSI HR component $(\mathbf{C})$ responses to the race according to PSI method. Symbols indicate main effect for PSI method: ${ }^{*} \mathrm{PSI}_{39.5 / 180}$ is

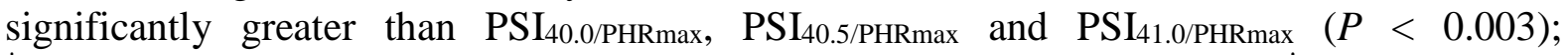
${ }^{\dagger} \mathrm{PSI}_{40.0 / \mathrm{PHRmax}}$ is significantly greater than $\mathrm{PSI}_{40.5 / \mathrm{PHR} \max }(P<0.001)$; and ${ }^{\dagger} \mathrm{PSI}_{40.0 / \mathrm{PHR} m a x}$ is significantly greater than PSI $_{41.0 / P H R m a x}(P<0.001)$.

Figure 4: Proportion of sample categorized to a heat strain rating based on peak PSI and according to PSI calculation method: (A) PSI $39.5 / 180$; (B) PSI $40.0 / \mathrm{PHRmax}_{2}$; (C) PSI $40.5 / \mathrm{PHRmax}$; and (D) PSI 41.0/PHRmax. 
Figure 1:
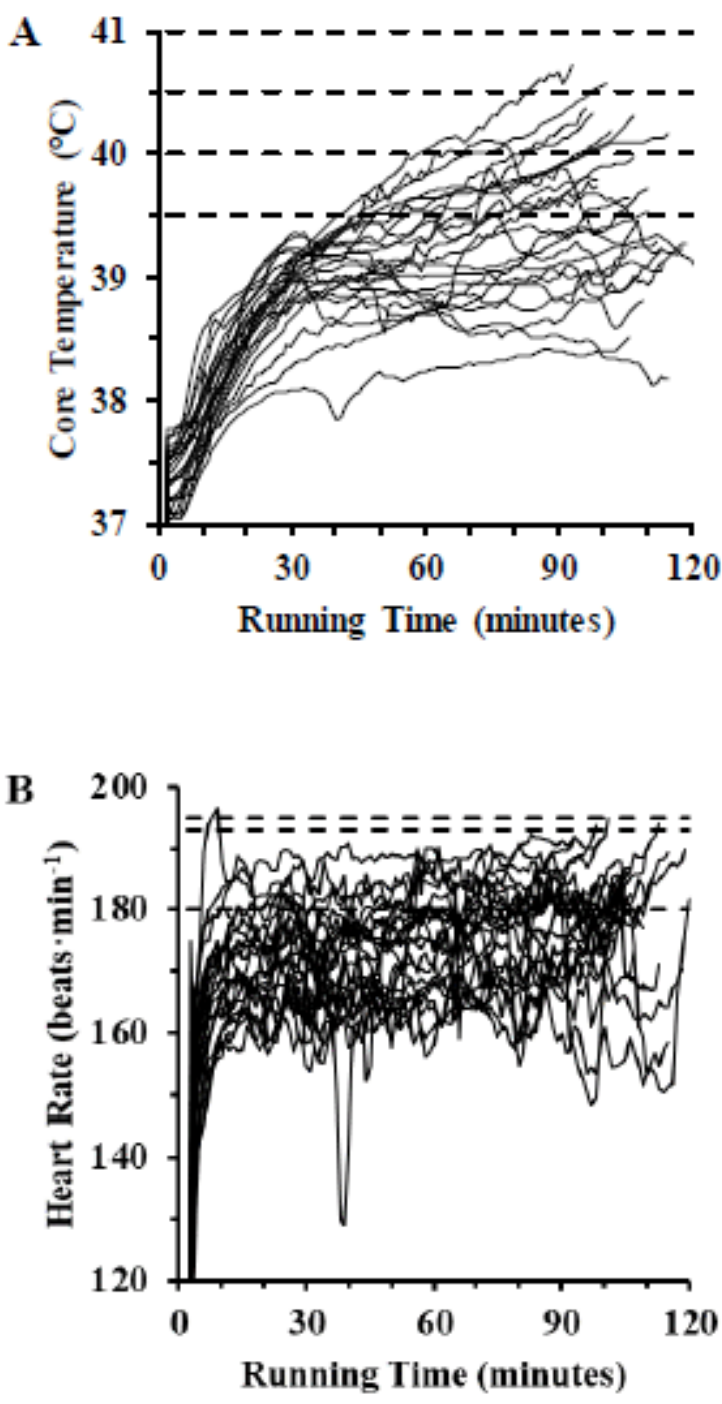
Figure 2:
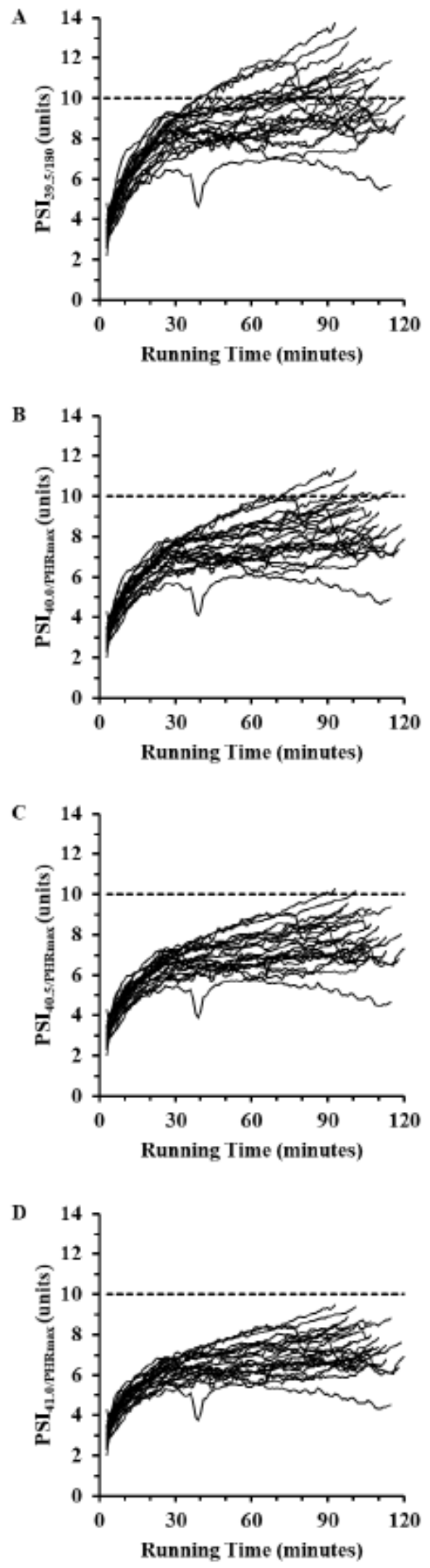
Figure 3:
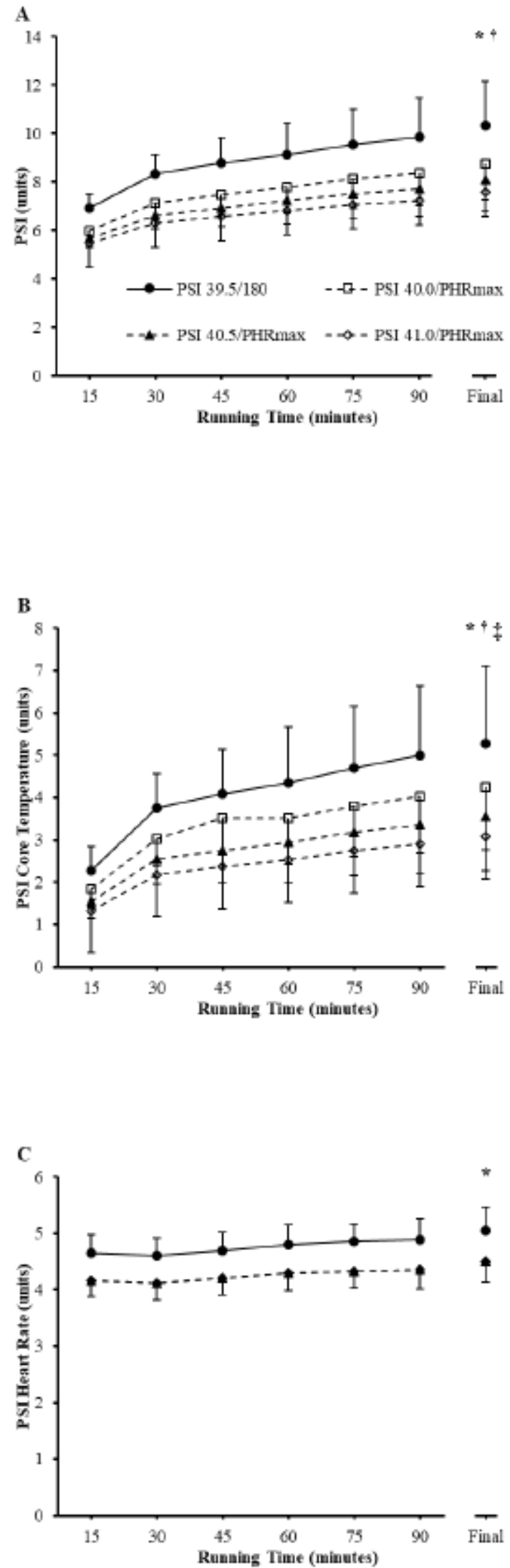
Figure 4:

A 口High (27) aVery high (2) UMarimal (>10)

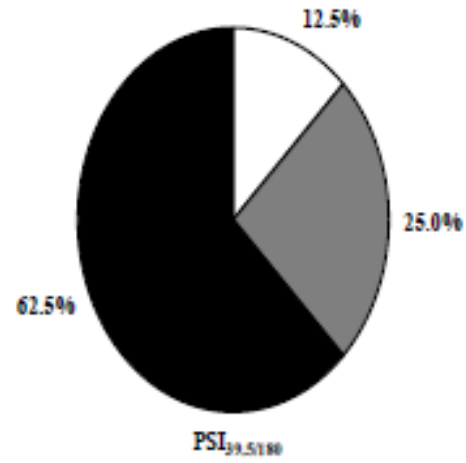

B 口High (27) पVery high (9) DMarimal (>10)

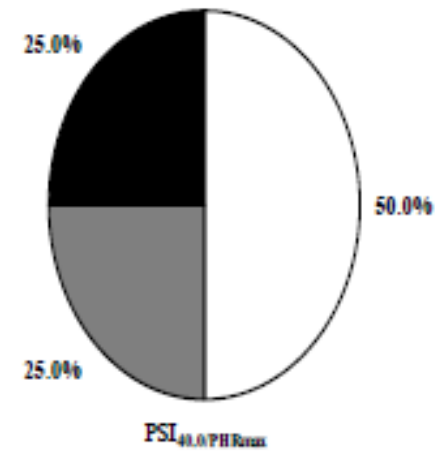

C DModerate (25) प High (2)

QVery high $(\geqslant 9)$ — Marimal $(>10)$

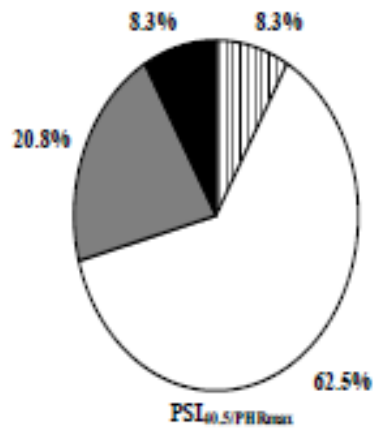

D aModerate (2) पHigh (27) aVery high (2)

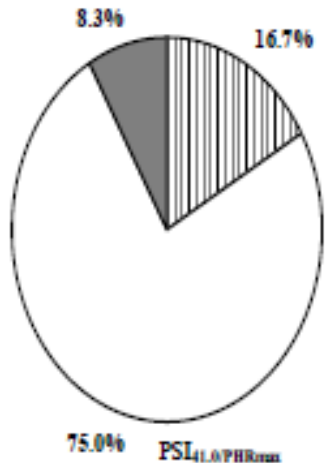

